\title{
Association of the host genetic factors, hypercholesterolemia and diabetes with mild influenza in an Iranian population
}

\author{
Parvaneh Mehrbod ${ }^{1 *}$, Sana Eybpoosh ${ }^{2}$, Behrokh Farahmand ${ }^{1}$, Fatemeh Fotouhi ${ }^{1}$ and \\ Majid Khanzadeh Alishahi ${ }^{3}$
}

\begin{abstract}
Background: Variation in host genetic factors may result in variation in the host immune response to the infection. Some chronic diseases may also affect individuals' susceptibility to infectious diseases. The aim of this study was to evaluate the association of the host genetic factors mostly involved in inflammation, as well as hypercholesterolemia and diabetes with mild flu in an Iranian population.
\end{abstract}

Methods: In this cross-sectional study, nasopharyngeal swab samples were collected from 93 patients referred to primary care centers of Markazi, Semnan, and Zanjan provinces (central Iran) due to flu-like symptoms between March 2015 and December 2018. Of these, PCR test identified 49 influenza A/H1N1 and 44 flu-negative individuals. Twelve single-nucleotide polymorphisms (SNPs) in RPAIN, FCGR2A, MBL-2, CD55, C1QBP, IL-10, TNF-a and an unknown gene were genotyped using iPLEX GOLD SNP genotyping analysis. Hypercholesterolemia and diabetes status was determined based on the physician diagnosis. Association of the host genetic variants, hypercholesterolemia and diabetes with mild $\mathrm{A} / \mathrm{H} 1 \mathrm{~N} 1$ flu was assessed with univariable and multivariable logistic regression analysis as implemented in Stata software (v.14). Statistical tests were considered as significant at 0.05 levels.

Results: Frequency of diabetes and hypercholesterolemia, as well as participants mean age was significantly higher in the flu-negative rather than the flu-positive group. Of 12 SNPs, nine did not show any significant association with mild flu in our study (rs1801274, rs1800451, rs2564978, rs361525, rs1800450, rs1800871, rs 1800872, rs1800896, rs 1800629). Possessing G vs. A allele in two SNPs (rs3786054 and rs8070740) was associated with a threefold increase in the chance of mild flu when compared to flu-negative patients $(95 \% \mathrm{Cl}: 1.1,22.0)$. Possessing $\mathrm{C}$ allele (vs. A) in the rs9856661 locus also increased the chance of mild flu up to 2 folds ( $95 \%$ Cl: 1.0, 10.0).

Conclusion: The results showed that possessing the $\mathrm{G}$ allele in either rs3786054 or rs 8070740 loci in $\mathrm{C} 1 \mathrm{QBP}$ and RPAIN genes, respectively, increased the risk of $\mathrm{H} 1 \mathrm{~N} 1$ infection up to $3.3 \mathrm{folds}$, regardless of the patient's age, BMI, diabetes, and hypercholesterolemia. Complementary functional genomic studies would shed more light on the underlying mechanism of human immunity associated with these genetic markers. The identified genetic factors may have the same role in susceptibility to similar respiratory infections with RNA viruses, like SARS, MERS and COVID-19. Future genetic association studies targeting these RNA viruses, especially COVID-19 is recommended. Studies on other ethnic groups would also shed light on possible ethnic variations in genetic susceptibility to respiratory RNA viruses.

\footnotetext{
*Correspondence: mehrbode@yahoo.com

${ }^{1}$ Influenza and Respiratory Viruses Department, Pasteur Institute of Iran, Tehran, Iran
}

Full list of author information is available at the end of the article

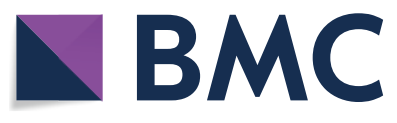

(c) The Author(s) 2021. Open Access This article is licensed under a Creative Commons Attribution 4.0 International License, which permits use, sharing, adaptation, distribution and reproduction in any medium or format, as long as you give appropriate credit to the original author(s) and the source, provide a link to the Creative Commons licence, and indicate if changes were made. The images or other third party material in this article are included in the article's Creative Commons licence, unless indicated otherwise in a credit line to the material. If material is not included in the article's Creative Commons licence and your intended use is not permitted by statutory regulation or exceeds the permitted use, you will need to obtain permission directly from the copyright holder. To view a copy of this licence, visit http://creativecommons.org/licenses/by/4.0/. The Creative Commons Public Domain Dedication waiver (http://creativeco mmons.org/publicdomain/zero/1.0/) applies to the data made available in this article, unless otherwise stated in a credit line to the data. 
Trial registry IR.PII.REC.1399.063

Keywords: Influenza, Genetic polymorphisms, Hypercholesterolemia, Diabetes, Iran

\section{Background}

Influenza A virus is one of the most important risk factors for human and animal health leading to severe respiratory infections [1]. New strains cause the epidemics among humans and animals. These viruses use the host cell system for their replication and propagation and affect host cell signaling pathways [2]. While most of the antiviral studies have focused on the genetic factors of viral agents that determine the severity of influenza and their impact on host immunity, there is lack of a comprehensive understanding of the host genetics which determine the severity and susceptibility of the respiratory disease [3]. The family clustering of highly pathogenic influenza A / H5N1 cases has led to the hypothesis that host genetic plays a key and critical role in the susceptibility to influenza infection [4-6].

The severity of the disease is usually associated with the host factors such as age (over 65 years), pregnancy, obesity and underlying diseases including lung, cardiovascular, renal or hepatic disease, chronic metabolic disorders (including diabetes) or immunodeficiency diseases [7]. Underlying diseases such as diabetes and hypercholesterolemia are associated with the highest risk and the most common contributing factors [8-10]. Ethnicity has also been identified as another risk factor for the susceptibility to $\mathrm{H} 1 \mathrm{~N} 1$ pandemic in multiple populations in the North America and Australia [11]. A key point for the studies of host innate immunity factors is the observation of increased mortality among young adults and children without pre-identified risk factors [12].

It has been shown that host polymorphisms affect the development of certain diseases and disorders by coding altered genes products or altering the transcriptional settings. In order to understand the pathogenicity of influenza virus, several parameters of both host and virus must be considered. These factors mainly include virus pathogenicity, host acquired immunity and host hereditary factors that have been taken into consideration in determining the severity of the disease, particularly after the 2009 epidemic $[3,13]$.

Several potential genetic polymorphisms have recently been described for the susceptibility to influenza infection; including genes which encode complement decay-accelerating factor (CD55), complement $1 \mathrm{C} 1 \mathrm{q}$ binding protein (C1QBP), Fc fragment of IgG receptor IIa (FCGR2A), interferon induced transmembrane protein 3 (IFITM3), tumor necrosis factor (TNF), replication protein A interacting protein (RPAIN), lymphotoxin alpha (LTA), and killer-cell inhibitory receptor (KIR) [14-18].

Genetic polymorphisms vary among individuals in different populations and usually include single nucleotide polymorphisms (SNP).

For example, the IFITM3 restricts the transcription of some viruses, especially those that enter the cell through endocytosis, such as influenza, HIV, and yellow fever [19-22]. In a study, the C allele frequency of IFITM3 rs12252 was shown high in Han Chinese population $(\mathrm{MAF}=0.528)$ [23]. This means that IFITM3 gene affects the severity of the disease. The expression of the rare rs12252-C allele in the IFITM3 gene results in a truncated protein that lacks 21 amino acids at the end of the amine, which reduces its impact on influenza infection control [23].

In our previous study, we examined rs12252 in the IFITM3 gene in an Iranian population from the selective provinces [24]. That was the first study to evaluate the association of IFITM3 rs12252 polymorphism with susceptibility to mild influenza with regards to diabetes, hypercholesterolemia and BMI in an Iranian population. Our results showed a significant positive association between mild influenza and the heterozygote $C$ allele at rs12252 $(P=0.008)$, not the homozygote $C$ allele $(P=0.406)$. The carriers of the $\mathrm{C}$ allele $(\mathrm{CT}+\mathrm{CC}$ genotype) were 5.92 times more at risk of mild influenza compared to the homozygote $\mathrm{T}$ allele $(P=0.007)$ [24].

Mannose-Binding Lectin-2 (MBL-2) gene is a member of the collagen-containing C-type lectin family. It is part of the innate immune system which is important for complement activation and opsonization [25]. MBL-2 encodes a calcium-dependent protein that plays an important role in innate immunity. The amount of circulating MBL-2 is mainly due to the single nucleotide polymorphisms occur in exon 1 and the promoter region. Different alleles of MBL-2 are associated with susceptibility to different infections [26-28].

Tumor necrosis factor- $\alpha$ (TNF- $\boldsymbol{\alpha})$ is a potent proinflammatory cytokine that plays role in the pathogenesis and development of various infectious diseases. However, IL-10 is a potent anti-inflammatory cytokine that plays an important role in regulating and reducing the cytotoxic inflammatory responses. Several polymorphisms in the promoter regions of these genes have been shown that affect directly the gene transcription and 
are associated with the development and progression of autoimmune and infectious diseases $[29,30]$.

CD55 or DAF (Decay-Accelerating Factor), encodes a glycoprotein involved in complement cascade regulation and is active in protecting host cells from damage of pathogenic microorganisms [31]. Studies have shown that the $\mathrm{T} / \mathrm{T}$ genotype in the rs2564978 CD55 gene promoter is associated with severe influenza A (H1N1) pdm09 [32].

Two SNPs in the C1QBP (rs3786054) and FCGR2A (rs1801274) genes have been reported to be associated with the cases of severe influenza in Mexico in 2009 [17]. The C1QBP gene encodes a protein that binds to the spherical heads of $\mathrm{C} 1 \mathrm{q}$ molecules and activates the classical complement pathway [17], while FCGR2A encodes a member of the Fc immunoglobulin receptor family which are found on the surface of phagocytic cells such as macrophages and neutrophils. It is involved in the process of phagocytosis and clearance of immune complexes [33].

RPAIN encodes a nucleoprotein that is involved in RNA movement and establishment [34]. The rs8070740 SNP in RPAIN has been shown to affect host immune response, or influenza A/H1N1 virus replication [17].

A significant association was also found between rs9856661 from an unknown gene located on chromosome 3 with the incidence of severe pneumonia in the patients with $\mathrm{A} / \mathrm{H} 1 \mathrm{~N} 1$ virus infection [17].

Consequently, based on this background and our previous study findings, further studies are needed to confirm the earlier findings and to explore if further SNPs are associated with susceptibility to mild flu in the Iranian population. Identifying genetic markers associated with mild flu can give us hints and indications about the mechanisms of susceptibility and resistance to this virus. Identifying the pathogenic and resistance mechanisms may have applications in drug and vaccine design. Tracking the host genetic factors in susceptibility and resistance to influenza virus (as a model for the respiratory RNA viruses) may be the basis for understanding the pathogenicity of similar viruses such as coronavirus. Twelve SNPs in 9 genes located on 6 chromosomes with partial global minor allele frequency (GMAF) were selected and analyzed using iPLEX $^{\circledR}$ and MassARRAY ${ }^{\circledR}$ system to genotype the desired alleles.

\section{Methods}

\section{Ethics statement}

The study objectives and processes were explained to all participants. Written informed consent was then obtained from them. The ethics committee of the Pasteur Institute of Iran reviewed and approved the protocol of this study (Ethics code: IR.PII.REC.1395.3).

\section{Participants and sample collection}

Nasopharyngeal swab samples were collected as fluid specimens in Viral Transport Media (VTM). The samples were collected from 93 patients who were suspected to influenza $\mathrm{A} / \mathrm{H} 1 \mathrm{~N} 1$ and referred to primary care centers of Markazi, Semnan, and Zanjan provinces (central Iran) from March 2015 to December 2018. Infection with influenza $\mathrm{A} / \mathrm{H} 1 \mathrm{~N} 1$ was confirmed by real-time PCR test. Our exclusion criteria were respiratory comorbidities, immune suppressive drugs consumption, and previous vaccination against influenza virus [24]. Based on real-time PCR test results, patients were classified into influenza $\mathrm{A} / \mathrm{H} 1 \mathrm{~N} 1$ positive $(\mathrm{n}=49)$ and negative $(\mathrm{n}=44)$ groups. The latter group was considered as having influenza-like illness (ILI).

Participants' age (year), sex, weight (kg), and height $(\mathrm{cm})$ were assessed at the time of their clinic visit. Diabetes (positive/negative) and hypercholesterolemia (positive/negative) status was also determined by the physician. Twelve SNPs in nine genes located on six chromosomes were genotyped. Genetic data of the SNPs analyzed are shown in Table 1.

\section{One-step quantitative real-time PCR for IAV detection}

Viral RNA was extracted from fluid specimen using High Pure Viral RNA Kit, according to the manufacturer's instructions (Roche, Switzerland). The extracted RNA was re-suspended in $50 \mu \mathrm{l}$ Elution Buffer and stored at $80{ }^{\circ} \mathrm{C}$ for real-time PCR assay. Primers and probes were designed and synthesized by SinaClon Co. (Iran) based on the latest WHO guideline. Real-time PCR reactions were performed as mentioned before [24].

\section{Genotyping of SNPs \\ Human DNA extraction}

All genomic DNA samples were extracted from the specimens using $\mathrm{DNP}^{\mathrm{TM}}$ High yield DNA Purification Kit, according to the manufacturer's instructions (Cinnagen, Iran) as stated before [24].

\section{IPLEX ${ }^{\circledR}$ method and MassARRAY ${ }^{\circledR}$ system for genotyping}

\section{the allelic variants}

The extracted DNA samples were transferred to Inqaba Biotech Co, South Africa, to determine the genotypes of the allelic variants using iPLEX $^{\circledR}$ and MassARRAY ${ }^{\circledR}$ platform (Sequenom MassARRAY ${ }^{\circledR}$ System, San Diego, USA). This SNP genotyping method involves an initial PCR reaction specific to the locus followed by single base extension using mass-modified primers containing terminal deoxyribonucleotides that binds immediately upstream of the polymorphism site. Using Matrix-Assisted Laser Desorption/Ionization-Time Of Flight (MALDI-TOF) Mass Spectrometry (MS), the specific mass of the amplified primer determines the SNP 
Table 1 Genetic data of the SNPs analyzed

\begin{tabular}{|c|c|c|c|c|c|}
\hline SNP & Chromosome & Gene & Location & Allele & GMAF \\
\hline rs8070740 & 17 & RPAIN & 3'UTR & $A>G$ & - \\
\hline rs1801274 & 1 & FCGR2A & Coding sequence & $A>C / A>G$ & 0.4302 \\
\hline rs1800451 & 10 & MBL-2 & Coding sequence & $C>T$ & 0.05466 \\
\hline rs2564978 & 1 & CD55 & Upstream transcript variant & $\mathrm{T}>\mathrm{C}$ & 0.2856 \\
\hline rs9856661 & 3 & Unknown & - & $A>C$ & - \\
\hline rs361525 & 6 & TNF-a & Intron variant & $G>A$ & - \\
\hline rs1800450 & 10 & MBL-2 & Missense variant & $C>T$ & 0.1212 \\
\hline rs3786054 & 17 & $\mathrm{C} 1 \mathrm{QBP}$ & Intron variant & $G>A$ & - \\
\hline rs1800871 & 1 & $\mathrm{IL}-10$ & Intron variant & $A>G$ & 0.4086 \\
\hline rs1800872 & 1 & $\mathrm{IL}-10$ & Intron variant & $T>G$ & 0.4091 \\
\hline rs1800896 & 1 & $\mathrm{IL}-10$ & Intron variant & $\mathrm{T}>\mathrm{C}$ & 0.3026 \\
\hline rs1800629 & 6 & TNF-a & Upstream transcript variant & $G>A$ & 0.0955 \\
\hline
\end{tabular}

UTR: untranslated region; GMAF: Global minor allele frequency

allele. This procedure involves the following steps: PrePCR for DNA ( 5 to $50 \mathrm{ng} / \mu \mathrm{l}$ ) and oligonucleotides preparation, PCR for target locus amplification using designed primers, Post-PCR for purification of the reaction with SAP (Shrimp alkaline phosphatase), Single base amplification with iPLEX system, Cleaning products with resin, Deployment of amplified products on SpectroCHIPs, and Products tracking with Mass Spectrometry with appropriate MALDI-TOF matrix [35]. The specifications of the oligos for iPLEX SNP genotyping are shown in Table 2.

\section{Genetic and statistical analysis}

Normality of continuous variables was confirmed by Kolmogorov Smirnoff test. Continuous and categorical data were described by mean $\pm S D$, and number (percentage), respectively. Distribution of demographic and clinical characteristics was compared between influenza A/ H1N1 group and the ILI group. Participants' mean age and BMI was compared between both groups using Independent $\mathrm{t}$-test. The two groups were compared regarding their gender, diabetes and hypercholesterolemia status using Pearson's Chi square test.

Genotype frequency of each SNP was compared between influenza A/H1N1 group and the ILI group using Pearson's Chi square test. Where expected genotype frequencies in more than $20 \%$ of the cells were less than five, Fisher's exact test was used instead. Univariable logistic regression analysis was used to test the size of each genotype crude effect on influenza A/H1N1. Investigated demographic and clinical characteristics whose distribution differed significantly between the two groups were included into a multivariable logistic regression in order to test the adjusted effect of each allele on influenza A/H1N1.
All statistical tests were two-tailed with a type I error of 0.05. Statistical analyses were performed in Stata software (version 11; Stata Corp, College Station, TX, USA).

\section{Results}

Demographical and clinical characteristics of influenza $\mathrm{A} / \mathrm{H} 1 \mathrm{~N} 1$ patients and influenza-like illness (ILI) patients are shown in Table 3. In both the A/H1N1 and ILI groups, participants were equally of both genders $\left(P_{\text {Pearson's chi square }}=0.460\right)$. The mean age of participants in both groups was 45 years. Participants in the ILI group were significantly of older ages than the $\mathrm{A} / \mathrm{H} 1 \mathrm{~N} 1$ group (mean age: 56.5 vs. 46.2 years, respectively. $P_{\mathrm{t} \text {-test }}=0.05$ ). Mean BMI levels was higher in the $\mathrm{A} / \mathrm{H} 1 \mathrm{~N} 1$ group (mean difference $=2.2 \mathrm{~kg} / \mathrm{m} 2$ ). This association, however, was not statistically significant $\left(P_{\mathrm{t} \text {-test }}=0.09\right)$. There was also a statistically significant association between diabetes $\left(P_{\text {Pearson's chi square }}=0.001\right)$ and hypercholesterolemia $\left(P_{\text {Fisher's exact test }}=0.03\right)$ statuses and $\mathrm{A} / \mathrm{H} 1 \mathrm{~N} 1$, in a way that the frequency of these comorbidities was lower in the $\mathrm{A} /$ H1N1 group rather than the ILI group (Table 3).

Logistic regression analysis showed that possessing G/G genotype in the rs3786054 and rs8070740 loci significantly increases the risk of H1N1 influenza while compared to the A/A genotype in these loci $\left(\mathrm{OR}_{\mathrm{rs} 3786054}=7.3\right.$; $\mathrm{OR}_{\mathrm{r} 80070740}=5.4$ ). The direction of this association was the same for the G/A genotypes, although with smaller magnitude $\left(\mathrm{OR}_{\mathrm{rs} 3786054}=2.6\right.$ and $\left.\mathrm{OR}_{\mathrm{rs} 8070740}=1.4\right)$; however, these associations were not statistically significant (Table 4). The results of the multivariable logistic regression analysis also showed that possessing the $\mathrm{G}$ allele in either rs3786054 or rs 8070740 loci, significantly increases the risk of H1N1 influenza up to 3.3 folds, regardless of the patient's age, BMI, diabetes, and hypercholesterolemia (Table 5). 
Table 2 The specifications of the oligos for iPLEX SNP genotyping

\begin{tabular}{|c|c|}
\hline Name of the Oligo & Sequence of Oligo \\
\hline rs8070740_W1_F & ACGTTGGATGGTCATAAGACCCAGATAGGC \\
\hline rs8070740_W1_R & ACGTTGGATGCAGACAAACCTAATGCTGCC \\
\hline rs8070740_W1_E & ATGCTGCCCTGCTA \\
\hline rs1801274_W1_F & ACGTTGGATGCTTCCAGAATGGAAAATCCC \\
\hline rs1801274_W1_R & ACGTTGGATGCTGTGACTGTGGTTTGCTTG \\
\hline rs1801274_W1_E & AGGTGGGATCCAAA \\
\hline rs1800451_W1_F & ACGTTGGATGAGAACAGCCCAACACGTACC \\
\hline rs1800451_W1_R & ACGTTGGATGAGTGATTGCCTGTAGCTCTC \\
\hline rs1800450_W1_E & agAAGATGGGCGTGATG \\
\hline rs1800451_W1_F & ACGTTGGATGAGAACAGCCCAACACGTACC \\
\hline rs1800451_W1_R & ACGTTGGATGAGTGATTGCCTGTAGCTCTC \\
\hline rs1800451_W1_E & TGGTTCCCCCTTTTCT \\
\hline rs2564978_W1_F & ACGTTGGATGGAACAATGTTCACTCCCTAC \\
\hline rs2564978_W1_R & ACGTTGGATGCGTCATCTCCTAGAACACTC \\
\hline rs2564978_W1_E & ACTCCCTACTGTGTTA \\
\hline rs9856661_W1_F & ACGTTGGATGTGCCAGCTTAGAAAACCTCC \\
\hline rs9856661_W1_R & ACGTTGGATGACCCACAGTGAACCTACAGA \\
\hline rs9856661_W1_E & TGCATGGCAGAGGGCT \\
\hline rs361525_W1_F & ACGTTGGATGGGATTTGGTGGGCAAAAGTC \\
\hline rs361525_W1_R & ACGTTGGATGAGATGTCAAACAGGGACTGC \\
\hline rs361525_W1_E & GGACTGCAAATTTCACA \\
\hline rs3786054_W1_F & ACGTTGGATGTATGCAACTCTGGCAGGCAC \\
\hline rs3786054_W1_R & ACGTTGGATGTCTCTTGACCTCGTGATCTG \\
\hline rs3786054_W1_E & aggCCATTCCACACAAGA \\
\hline rs1800871_W1_F & ACGTTGGATGATGCTAGTCAGGTAGTGCTC \\
\hline rs1800871_W1_R & ACGTTGGATGGGTGTACCCTTGTACAGGTG \\
\hline rs1800871_W1_E & CTTGTACAGGTGATGTAA \\
\hline rs1800872_W1_F & ACGTTGGATGTCCTCAAAGTTCCCAAGCAG \\
\hline rs1800872_W1_R & ACGTTGGATGAAAGGAGCCTGGAACACATC \\
\hline rs1800872_W1_E & ccCtACTGGCTTCCTACAG \\
\hline rs1800896_W1_F & ACGTTGGATGATTCCATGGAGGCTGGATAG \\
\hline rs1800896_W1_R & ACGTTGGATGGACAACACTACTAAGGCTTC \\
\hline rs1800896_W1_E & $\operatorname{tgACCTATCCCTACTTCCCC~}$ \\
\hline rs1800629_W1_F & ACGTTGGATGGGAGGCAATAGGTTTTGAGG \\
\hline rs1800629_W1_R & ACGTTGGATGCTGATTTGTGTGTAGGACCC \\
\hline rs1800629_W1_E & cgGGAGGCTGAACCCCGTCC \\
\hline
\end{tabular}

The crude effect of rs9856661 genotypes on the H1N1 influenza risk was not statistically significant, probably due to small number of observations within each genotype category. The allelic OR, however, showed that possessing the $\mathrm{A}$ allele (rather than the $\mathrm{C}$ allele) significantly increased the risk of H1N1 influenza up to two folds both in the crude analysis and after adjustment for the abovementioned demographics and comorbidities (Table 5). The association of other SNPs with H1N1 influenza was
Table 3 Demographical and clinical characteristics of influenza A/H1N1 patients and influenza-like illness (ILI) patients

\begin{tabular}{|c|c|c|c|}
\hline \multirow[t]{2}{*}{ Characteristics } & \multicolumn{3}{|l|}{ Groups } \\
\hline & Influenza A/H1N1 & ILI & $P$ value \\
\hline \multicolumn{4}{|l|}{ Sex } \\
\hline Male & $26(53.1)$ & $20(45.5)$ & \multirow[t]{2}{*}{$0.463^{\S}$} \\
\hline Female & $23(46.9)$ & $24(54.5)$ & \\
\hline \multicolumn{4}{|l|}{ Age $_{\text {(Year) }}$} \\
\hline Mean $\pm S D$ & $46.2 \pm 22.5$ & $56.5 \pm 23.7$ & $0.05^{*}$ \\
\hline$<45$ & $21(42.9)$ & $10(22.7)$ & \multirow[t]{3}{*}{-} \\
\hline $45-64$ & $7(14.2)$ & $12(27.3)$ & \\
\hline$\geq 65$ & $21(42.9)$ & $22(50.0)$ & \\
\hline $\mathrm{BMI}_{\text {Mean } \pm S \mathrm{SD}}$ & $26.4 \pm 1.1$ & $24.2 \pm 0.7$ & $0.09^{*}$ \\
\hline \multicolumn{4}{|l|}{ Diabetes } \\
\hline Negative & $42(85.7)$ & $24(54.5)$ & \multirow[t]{2}{*}{$0.001^{\S}$} \\
\hline Positive & $7(14.3)$ & $20(45.5)$ & \\
\hline \multicolumn{4}{|c|}{ Hypercholesterolemia } \\
\hline Negative & $46(93.9)$ & $34(77.3)$ & \multirow[t]{2}{*}{$0.03^{\mathrm{a}}$} \\
\hline Positive & $3(6.1)$ & $10(22.7)$ & \\
\hline
\end{tabular}

*Independent t-test

§Pearson's chi square test

"Fisher's exact test

not statistically significant either in crude or adjusted analyses (Tables $4 \& 5$ ).

\section{Discussion}

In the present study, we investigated the genetic susceptibility of the host to influenza virus infection by incorporating hypercholesterolemia and diabetes factors. The alleles and their genotypes were examined to determine whether the polymorphisms of the studied genes are associated with the susceptibility to influenza virus in this population with a preference for hypercholesterolemia and diabetes. Host and pathogen genetic determinants are important to evaluate pathogenesis of infectious disease. Several polymorphisms which have been known for the susceptibility to influenza infection include CD55, C1QBP, FCGR2A, IFITM3, TNF, RPAIN, LTA and KIR [14-18]. The protein products of the tested SNPs were reported to be associated with inflammatory reactions [36].

In this study, we examined a wide range of human genetic variants in different genes involved in immune response against viral infection in order to explore their potential association with mild influenza in human. Mild influenza causes mild respiratory infection, pulmonary dysfunction and clinical manifestation. It can resolve on its own without significant symptoms and without need for hospitalization. From 12 studied SNPs that are 
Table 4 Frequency of 12 SNPs and their association with influenza A/H1N1 infection

\begin{tabular}{|c|c|c|c|c|c|}
\hline \multirow[t]{2}{*}{ Gene and genotype } & \multicolumn{2}{|l|}{ Groups } & \multirow[t]{2}{*}{$P$} & \multirow[t]{2}{*}{ Crude $\mathrm{OR}^{\S}$} & \multirow[t]{2}{*}{$95 \% \mathrm{Cl}$} \\
\hline & $\begin{array}{l}\mathrm{ILI} \\
\mathrm{n}(\%)\end{array}$ & $\begin{array}{l}\text { Influenza A/H1N1 } \\
\mathrm{n}(\%)\end{array}$ & & & \\
\hline \multicolumn{6}{|l|}{ rs 1800450* } \\
\hline$C C$ & $33(84.6)$ & $40(88.9)$ & 0.734 & 1 & - \\
\hline TT & $1(2.6)$ & $0(0)$ & & - & - \\
\hline TC & $5(12.8)$ & $5(11.1)$ & & 0.8 & $0.2,3.1$ \\
\hline \multicolumn{6}{|l|}{$\operatorname{rs} 1800451^{*}$} \\
\hline CC & $38(97.4)$ & $45(100)$ & 0.464 & - & - \\
\hline CT & $1(2.6)$ & $0(0)$ & & - & - \\
\hline \multicolumn{6}{|l|}{ rs $1800629^{*}$} \\
\hline GG & $36(85.7)$ & $39(84.8)$ & 0.268 & 1 & - \\
\hline$A A$ & $2(4.8)$ & $0(0)$ & & - & - \\
\hline GA & $4(9.5)$ & $7(15.2)$ & & 1.6 & $0.4,6.0$ \\
\hline \multicolumn{6}{|l|}{ rs1800871 } \\
\hline GG & $17(43.6)$ & $19(44.2)$ & 0.425 & 1 & - \\
\hline AA & $2(5.1)$ & $6(14.0)$ & & 2.7 & $0.5,15.1$ \\
\hline GA & $20(51.3)$ & $18(41.8)$ & & 0.8 & $0.3,2.0$ \\
\hline \multicolumn{6}{|l|}{ rs 1800872} \\
\hline GG & $18(45.0)$ & $18(47.4)$ & 0.616 & 1 & - \\
\hline TT & $2(5.0)$ & $4(10.5)$ & & 2.0 & $0.3,12.3$ \\
\hline GT & $20(50.0)$ & $16(42.1)$ & & 0.8 & $0.3,2.0$ \\
\hline \multicolumn{6}{|l|}{ rs 1800896} \\
\hline CC & $2(5.3)$ & $4(9.8)$ & 0.832 & 1 & - \\
\hline TT & $20(52.6)$ & $20(48.8)$ & & 0.5 & $0.1,3.1$ \\
\hline $\mathrm{CT}$ & $16(42.1)$ & $17(41.5)$ & & 0.5 & $0.1,3.3$ \\
\hline \multicolumn{6}{|l|}{ rs 1801274} \\
\hline GG & $5(12.2)$ & $9(22.0)$ & 0.056 & 1 & - \\
\hline AA & $12(29.3)$ & $19(46.3)$ & & 0.9 & $0.2,3.3$ \\
\hline GA & $24(58.5)$ & $13(31.7)$ & & 0.3 & $0.1,1.1$ \\
\hline \multicolumn{6}{|l|}{ rs2564978 } \\
\hline CC & $25(65.8)$ & $29(69.1)$ & 0.938 & 1 & - \\
\hline TT & $3(7.9)$ & $4(9.5)$ & & 1.2 & $0.2,5.6$ \\
\hline $\mathrm{CT}$ & $10(26.3)$ & $9(21.4)$ & & 0.8 & $0.3,2.2$ \\
\hline \multicolumn{6}{|l|}{ rs361525 } \\
\hline GG & $8(20.5)$ & $10(23.8)$ & 0.681 & 1 & - \\
\hline AA & $14(35.9)$ & $11(26.2)$ & & 0.6 & $0.2,2.1$ \\
\hline GA & $17(43.6)$ & $21(50.0)$ & & 1.0 & $0.3,3.1$ \\
\hline \multicolumn{6}{|l|}{ rs3786054 } \\
\hline AA & $7(23.3)$ & $2(5.9)$ & 0.027 & 1 & - \\
\hline GG & $11(36.7)$ & $23(67.7)$ & & 7.3 & $1.3,41.1$ \\
\hline AG & $12(40.0)$ & $9(26.5)$ & & 2.6 & $0.4,15.8$ \\
\hline \multicolumn{6}{|l|}{ rs8070740 } \\
\hline$A A$ & $13(31.7)$ & $28(65.1)$ & 0.007 & 1 & - \\
\hline GG & $10(24.4)$ & $4(9.3)$ & & 5.4 & $1.4,20.4$ \\
\hline GA & $18(43.9)$ & $11(25.6)$ & & 1.5 & $0.4,6.1$ \\
\hline \multicolumn{6}{|l|}{ rs9856661 } \\
\hline$C C$ & $5(12.5)$ & $4(9.8)$ & 0.272 & 1 & - \\
\hline $\mathrm{AA}$ & $19(47.5)$ & 27 (65.8) & & 1.8 & $0.4,7.5$ \\
\hline CA & $16(40.0)$ & $10(24.4)$ & & 0.8 & $0.2,3.6$ \\
\hline
\end{tabular}


Table 4 (continued)

*Odds ratio has not been estimated for the genotypes with zero observations

${ }^{\S}$ Significant odds ratios (ie., $P<0.05$ ) are bolded (Prs 3786054: 0.0140; Prs 8070740: 0.0093). ILI: influenza like illness; OR: odds ratio

Table 5 Crude and adjusted allelic risk of influenza A/H1N1 infection in relation to alleles of polymorphisms studied

\begin{tabular}{|c|c|c|c|c|}
\hline $\begin{array}{l}\text { Gene and } \\
\text { genotype* }\end{array}$ & Crude $O R^{a}$ & $95 \% \mathrm{Cl}$ & Adjusted $O R^{\S a}$ & $95 \% \mathrm{Cl}$ \\
\hline \multicolumn{5}{|l|}{ rs $1800450(/ C)$} \\
\hline $\begin{array}{l}\mathrm{T} \\
\text { rs1800629 (/G) }\end{array}$ & 0.7 & $0.2,2.5$ & 0.9 & $0.1,6.0$ \\
\hline $\begin{array}{l}\text { A } \\
\text { rs1800871 (/A) }\end{array}$ & 1.1 & $0.3,3.5$ & 1.1 & $0.1,8.5$ \\
\hline $\begin{array}{l}\mathrm{G} \\
\text { rs1800872(/G) }\end{array}$ & 1.0 & $0.4,2.5$ & 1.1 & $0.3,4.1$ \\
\hline $\begin{array}{l}\mathrm{T} \\
\text { rs1800896 (/T) }\end{array}$ & 0.9 & $0.4,2.2$ & 1.0 & $0.3,3.7$ \\
\hline $\begin{array}{l}\text { C } \\
\text { rs1801274(/G) }\end{array}$ & 1.2 & $0.5,2.8$ & 2.5 & $0.6,9.4$ \\
\hline $\begin{array}{l}\text { A } \\
\text { rs2564978 (/C) }\end{array}$ & 2.1 & $0.8,5.2$ & 1.5 & $0.4,6.7$ \\
\hline $\begin{array}{l}\mathrm{T} \\
\mathrm{rs361525}(/ \mathrm{A})\end{array}$ & 0.9 & $0.3,2.2$ & 0.4 & $0.1,1.6$ \\
\hline $\begin{array}{l}\mathrm{G} \\
\text { rs3786054 (/A) }\end{array}$ & 1.6 & $0.6,4.1$ & 1.9 & $0.4,8.6$ \\
\hline $\begin{array}{l}\mathrm{G} \\
\text { rs8070740 (/A) }\end{array}$ & 3.3 & $1.3,11.1$ & 3.3 & $1.1,22.0$ \\
\hline $\begin{array}{l}\mathrm{G} \\
\text { rs9856661 (/A) }\end{array}$ & 3.3 & $1.7,10$ & 3.3 & $1.1,14.3$ \\
\hline C & 2.0 & $1.1,5.0$ & 2.0 & $1.0,10.0$ \\
\hline
\end{tabular}

*Allele frequencies have been considered for defining the baseline category in the logistic regression analysis. In fact, the alleles with higher frequency were considered as the baseline category in the logistic regression

"Significant odds ratios (ie., $P<0.05$ ) are bolded

${ }^{\S}$ The odds ratios are adjusted for the confounding effect of age, body mass index, diabetes (positive/negative), and hypercholesterolemia (positive/ negative). OR: odds ratio

believed to be associated with immune response against viral infection, nine (rs1800450, rs1800629, rs1800871, rs1800872, rs1800896, rs1801274, rs1801274, rs2564978, rs361525) did not show any significant association with mild flu in our study. Three SNPs (rs3786054, rs8070740, rs9856661), however, revealed evidence on such associations. Possessing G allele (vs. A) in rs3786054 and rs 8070740 loci is associated with a threefold increase in the chance of mild flu when compared to ILI patients. Possessing C allele (vs. A) in the rs9856661 locus also increases the chance of mild flu up to 2 folds.
In regards to IFITM3, Zhang et al., estimated that patients carrying the CC genotype in their rs 12252 IFITM3 were six times more at risk of severe infection than those with the CT and TT genotypes. Higher levels of the CC allele in the Han Chinese population than in White population may put the Chinese at higher risk for developing severe illness following influenza virus infection. IFITM3 may also play an important role in virus replication and proliferation after initial infection [23]. Recently, with extensive analysis, the close association of the rs12252-C allele with influenza susceptibility has been demonstrated in two Han Chinese and English whites populations [37]. However, in some populations such as Caucasian (MAF $=0.041)$ [23] and infants and children populations [38], little correlation was found between this allele and susceptibility to influenza. Zhang et al., in 2013 demonstrated the association of the $C$ allele at rs12252 in the IFITM3 gene in different populations of Chinese, Japanese, Northern European and English with the 2009 pandemic influenza [23]. In a recent review study, the effect of rs12252 in IFITM3 gene on influenza infection was investigated demographically [39]. In our previous study on IFITM3, BMI, diabetes, and hypercholesterolemia in an Iranian population, no association was found between mild influenza and the homozygote allele rs $12252 \mathrm{C}$ and these underlying factors. The carriers of the $\mathrm{C}$ allele were more at risk of mild influenza compared to the homozygote $\mathrm{T}$ allele [24].

TNF- $\boldsymbol{\alpha}$ functions in homeostasis and disease pathogenesis. It induces pathogenic epigenetic modifications and promotes enhanced inflammatory responses even to minor environmental challenges [40]. IL-10 plays pleiotropic role in immunoregulation and inflammation. It can block NF-kB activity and is involved in the regulation of the JAK-STAT signaling pathway. Mutations in this gene have been shown to be associated with the increased susceptibility to HIV-1 infection [provided by RefSeq, May 2020]. This cytokine selectively impacts the expression of Th17-associated cytokines during influenza infection [41]. IL-10 can impair T cell priming in the early stages of adaptive immunity, a mechanism that viruses use to promote their persistence by infecting antigen presenting cells (APCs). IL-10 effects are more subtle in the immune response during acute infections [42].

The TNF polymorphisms were shown to be associated with risk of infection by influenza $\mathrm{A} / \mathrm{H} 1 \mathrm{~N} 1$ virus during the pandemic in Mexico in 2009. Carriers of the 
rs1800629 G/A genotype were associated with high levels of blood urea nitrogen [18]. The role of rs361525 of TNF- $\alpha$ gene located on the short arm of chromosome 6 in the course of infection with 2009 H1N1 influenza virus was confirmed [14]. TNF- $\alpha$ rs361525 G/A genotype was associated with an increased risk of disease severity. TNF- $\alpha$ rs 1800629 G/G genotype and IL-10 rs1800872 and rs1800896 were also associated with increased disease severity [43].

Genotype G/G and G/T of IL-10 rs1800872 were associated with increased risk of infection with influenza A/ H3N2 virus. This might be due to anti-inflammatory nature of IL-10 that prevents NK and T cell activities to affect the strong inflammatory action after first infection [44]. In the study by Keshavarz et al., the frequencies of IL-10 rs1800872 and IL-28 rs8099917 were shown not to be associated with influenza disease [45] which was in accordance with our results.

The IL-10 rs 1800872 is related to increased intensity of autoimmune and infectious diseases which can control the transcription and expression of IL-10 [46]. The same polymorphism was investigated by Ferdinand et al,. They studied the frequency of TNF and MBL SNPs, located on the chromosomes 6 and 10, respectively, in children and adolescents with fatal influenza infection and compared the outcome with the control group. They reported that influenza cases leading to death with concomitant methicillin-resistant Staphylococcus aureus (MRSA) infection had a higher incidence of low-production MBL2 genotype compared to the cases of death without MRSA co-infection [47]. A study conducted on 246 patients infected with A/H1N1pdm09 virus in India, suggested that SNPs in the IL-10 and TNF- $\alpha$ genes might be associated with disease severity in influenza A/H1N1pdm09infected patients. In this study, TNF- $\alpha$ rs1800629, IL-10 rs1800872, IL-10 rs1800896 were genotyped by PCR along with other genotypes. TNF- $\alpha$ rs1800629 G/A genotype showed significantly higher frequency in severe cases compared to the mild cases. IL-10 rs1800896 G allele, in dominant mode, was significantly negatively associated with the disease severity. IL-10 rs1800896 C/A genotype was significantly associated with fatality in influenza A/H1N1pdm09 infections [48], however, in our study we could not find any association of these SNPS with influenza infection.

MBL-2 gene different alleles are associated with susceptibility to different infections [26-28].

This gene encodes the soluble mannose-binding lectin which belongs to the collectin family and is considered as an important element in the innate immune system. This protein binds to mannose and $\mathrm{N}$-acetylglucosamine on different microorganisms and viruses including influenza virus, HIV and SARS-CoV. This binding activates the classical complement pathway [provided by RefSeq, Jun 2020].

Codon 54 of this gene is more prevalent in White population than codons 52 and 57. Individuals with A allele in codon 54 have lower levels of MBL-2 protein compared to those carrying codon 52 . This MBL-2 protein is disabled for classical complement activation [49]. Among the polymorphisms of this gene, codon 54 is associated with susceptibility to infection $[50,51]$. Recently, in the evaluation of MBL gene variants in pediatric influenza-related illness, MBL deficiency was suggested as no serious risk factor for very severe influenza infection in children and adolescents [52].

In a matched case-control study conducted in Brazil, the association between MBL2, CLEC5A, ITGB3 and CCR5 genes and dengue severity was investigated in children. They found no association in single SNP analysis. However, the allele rs7095891G/rs1800450C/ rs1800451C/ rs4935047A/ rs930509G/ rs2120131G/ rs2099902C were significantly associated to the risk of severe dengue when MBL2 SNPs were combined in haplotypes [53], however, in our study we could not find any association of rs1800450 and rs1800451 SNPs with influenza infection.

FCGR is a glycoprotein which binds to the Fc region of IgG and activates immune response to control pathogens [54]. FCGR2A is one of the five genes located on chromosome 1, which encode receptors with low affinity for this glycoprotein. The activation or inhibition of these receptors regulates the local inflammatory response [55]. This gene encodes a cell surface receptor found on phagocytic cells such as macrophages and neutrophils, and is involved in the process of phagocytosis and clearing of immune complexes [provided by RefSeq, Oct 2008].

The genetic variant of the IgG Fc receptor at position 131 has been shown to be associated with susceptibility to inflammatory and infectious diseases like Kawasaki disease [56] and pneumococcal diseases [57]. Researchers studied the rs1801274 variant of the FCGR2A gene and concluded that this variant may be related to greater susceptibility to severe forms of flu [17]. Maestri and colleagues investigated this SNP for His131Arg substitution in Brazilian admixed population diagnosed with $\mathrm{H} 1 \mathrm{~N} 1 \mathrm{pdm} 09$ infection. They detected no association of rs1801274 polymorphism with severe disease in this population [15]. In the study on the patients from northern Greece suffered from influenza $\mathrm{A}(\mathrm{H} 1 \mathrm{~N} 1)$ pdm09 disease, no significant difference was either detected for FCGR2A genotypes neither with fatality nor disease severity [58] which was in line with our study outcome. However, this study found relationship between rare $\mathrm{T} / \mathrm{T}$ genotype of CD55 rs2564978 and rare A/A genotype of C1QBP 
rs3786054 with increased death risk but not with disease severity [58].

CD55 may play an important role in the presentation of disease. It functions to protect the host cells from complement attack and inhibits the complement cascade. The high expression level of CD55 in human lung may reflect its critical role to prevent lung from complement-mediated tissue damage as a result of longterm evolutionary pressure [16].

C1QBP inhibits the complement activation [59]. It was shown to be involved in HIV-1 replication, probably by contributing to splicing of viral RNA [60].

Carriers of $\mathrm{T} / \mathrm{T}$ rs2564978 genotype in CD55 gene in Chinese population have been shown to be significantly associated with severe H1N1 infection [16]. Studies have shown that patients with $\mathrm{T} / \mathrm{T}$ genotype at rs2564978 in CD55 gene contained lower levels of CD55 in peripheral blood mononuclear cells compared to the patients with the $\mathrm{C} / \mathrm{C}$ and $\mathrm{C} / \mathrm{T}$ genotypes which cannot regulate complement cascade [32]. The association between IFITM3 rs12252, and CD55 rs2564978 SNPs and influenza H7N9/H1N1 pdm09 clinical outcomes was examined in Chinese population. The overexpression of homozygote CC genotype at rs12252 in IFITM3 among fatal cases was detected and CD55 TT genotype at rs 2564978 was linked to severity of the disease [61]. The CD55 rs2564978 SNP did not show significant association with influenza in our study but C1QBP rs3786054 G allele (vs. A) showed association with a threefold increase in the chance of mild flu.

In regards to rs8070740 and rs9856661 at RPAIN and unknown genes, respectively, it was suggested that these genes polymorphisms might impact the susceptibility to severe pneumonia in $\mathrm{A} / \mathrm{H} 1 \mathrm{~N} 1$ infection [17].

RPAIN in short name; hRIP, mediates the import of replication protein A (RPA) complex into the nucleus, possibly via interaction with importin beta. The isoform 2 of this gene is sumoylated by ubiquitin-like protein and mediates the localization of RPA complex into the nucleus, thereby participating in DNA metabolism [62].

Our study confirmed these results as rs9856661C allele increased the chance of mild flu up to 2 folds in Iranian population.

Our study has notable strengths, including: a) novel method of genotyping; b) study on the Iranian ethnicity for these SNPs for the first time; and c) high number of SNPs analyzed in a single study. In spite of the value of the first genetic association study of its kind in Iran, this study has a number of limitations, particularly its small sample size. Further studies on larger sample sizes will be warranted.

\section{Conclusion}

The results showed that possessing the $G$ allele in either rs3786054 or rs8070740 loci in C1QBP and RPAIN genes, respectively, increased the risk of $\mathrm{H} 1 \mathrm{~N} 1$ infection up to 3.3 folds, regardless of the patient's age, BMI, diabetes, and hypercholesterolemia. Future functional genomic studies on identified genetic markers may provide clues to the molecular targets that can be used for therapies, as well as effective vaccines. Given multiple factors such as vaccination, virus subtype and host genetic factor play role in the immune response against influenza, systems biology methods are needed to illuminate the interaction between these factors and their role in susceptibility to influenza. The identified genetic and clinical factors may also be associated with susceptibility to other respiratory RNA viruses, like Severe Acute Respiratory Syndrome (SARS), Middle East Respiratory Syndrome (MERS) and COVID-19. Future genetic association studies targeting these RNA viruses, especially COVID-19 is recommended to provide better understanding of host the immune response against the virus $[63,64]$. A better understanding of the biological pathways leading to severe viral disease can be helpful for more effective treatments. New discoveries may generate hypotheses for drug repurposing and may estimate the country's need for vaccine design and production. Also, studies on other ethnic groups would also shed the light on possible ethnic variations in genetic susceptibility to respiratory RNA viruses.

\section{Abbreviations}

APCs: Antigen presenting cells; C1QBP: Complement 1 C1q binding protein; CD55: Complement decay-accelerating factor; DAF: Decay-accelerating factor; FCGR2A: Fc fragment of IgG receptor Ila; GMAF: Global minor allele frequency; IAV: Influenza A virus; IFITM3: Interferon induced transmembrane protein 3; ILI: Influenza like illness; KIR: Killer-cell inhibitory receptor; LTA: Lymphotoxin alpha; MALDI-TOF: Matrix-assisted laser desorption/ionization-time of flight; MBL-2: Mannose-binding Lectin-2; MS: Mass spectrometry; OR: Odds ratio; RPA: Replication protein A; RPAIN: Replication protein A interacting protein; SAP: Shrimp alkaline phosphatase; SNP: Single nucleotide polymorphism; TNF: Tumor necrosis factor; UTR: Untranslated region; VTM: Viral transport media.

\section{Acknowledgements}

The authors would like to thank Inqaba Biotech Co., South Africa for their cooperation in SNP genotyping using iPLEX GOLD SNP genotyping platform.

\section{Authors' contributions}

Conceived and designed the experiments: PM; performed the experiments: PM; Analyzed the data: SE, PM; Contributed reagents/materials: PM, BF, FF; Wrote the paper: PM, SE; Comprehensive reading the manuscript: all authors. All authors read and approved the final manuscript.

\section{Funding}

This study was funded by Pasteur institute of Iran, Iran (grant number 1188).

Availability of data and materials

All data in case of need are available. 


\section{Ethics approval and consent to participate}

Clinical investigation was conducted according to the principles expressed in the Declaration of Pasteur Institute of IRAN. This research was reviewed and approved by the Ethics Committee of Pasteur Institute of IRAN (Protocol Number IR.PII.REC.1399.063).

\section{Consent for publication}

Written informed consent was obtained from the patients or the guardians of the patients participated in this research.

\section{Competing interests}

Authors (Parvaneh Mehrbod, Sana Eybpoosh, Fatemeh Fotouhi, Behrokh Farahmand) declare that they have no conflicts of interest.

\section{Author details}

${ }^{1}$ Influenza and Respiratory Viruses Department, Pasteur Institute of Iran, Tehran, Iran. ${ }^{2}$ Department of Epidemiology and Biostatistics, Research Centre for Emerging and Reemerging Infectious Diseases, Pasteur Institute of Iran, Tehran, Iran. ${ }^{3}$ Private Practitioner, Mashhad, Iran.

Received: 27 July 2020 Accepted: 2 January 2021

Published online: 25 March 2021

\section{References}

1. Fedson DS. Confronting an influenza pandemic with inexpensive generic agents: can it be done? Lancet Inf Dis. 2008;8:571-6.

2. Herold S, Ludwig S, Pleschka S, Wolff T. Apoptosis signaling in influenza virus propagation, innate host defense, and lung injury. J Leukoc Biol. 2012:92:75-82.

3. Horby P, Nguyen NY, Dunstan SJ, Baillie JK. The role of host genetics in susceptibility to influenza: a systematic review. PLoS ONE. 2012;7:e33180.

4. Aditama, T.Y., Samaan, G., Kusriastuti, R., Purba, W.H., Misriyah, Santoso, H., Bratasena, A., Maruf, A., Sariwati, E., Setiawaty, V., et al. Risk factors for cluster outbreaks of Avian influenza A H5N1 infection, Indonesia. Clinical Infectious Diseases, 2011. 53: 1237-1244.

5. Horby P, Sudoyo H, Viprakasit V, Fox A, Thai PQ, Yu H, Davila S, Hibberd M, Dunstan SJ, Monteerarat Y, et al. What is the evidence of a role for host genetics in susceptibility to influenza A/H5N1? Epidemiol Infect. 2010;138:1550-8.

6. Sedyaningsih ER, Isfandari S, Setiawaty V, Rifati L, Harun S, Purba W, Imari S, Giriputra S, Blair PJ, Putnam SD, et al. Epidemiology of cases of H5N1 virus infection in Indonesia, July 2005-June 2006. J Infect Dis. 2007;196:522-7.

7. CDC. People at high risk of developing flu-related complications. 2017 [cited 2017].

8. Campbell A, Rodin R, Kropp R, Mao Y, Hong Z, Vachon J, Spika J, Pelletier L. Risk of severe outcomes among patients admitted to hospital with pandemic (H1N1) influenza. Can Med Assoc J. 2010;182:349-55.

9. HanslikT, Boelle PY, Flahault A. Preliminary estimation of risk factors for admission to intensive care units and for death in patients infected with $A(H 1 N 1) 2009$ influenza virus, France, 2009-2010. PLoS Curr. 2010;5:2157-3999.

10. Valdez R, Narayan KMV, Geiss LS, Engelgau MM. The impact of diabetes mellitus on mortality associated with pneumonia and influenza among non-hispanic black and white US adults. Am J Public Health. 1999;89:1715-21.

11. Webb SA, Pettilä V, Seppelt I, Bellomo R, Bailey M, Cooper DJ, Cretikos M, Davies AR, Finfer S, Harrigan PW, et al. Critical care services and 2009 H1N1 influenza in Australia and New Zealand. N Engl J Med. 2009;361:1925-34.

12. Ribeiro, A.F., Pellini, A.C.G., Kitagawa, B.Y., Marques, D., Madalosso, G., N.F.G., d.C., Fred, J., Albernaz, R.K.M., Carvalhanas, T.R.M.P., Zanetta, D.M.T. Risk factors for death from influenza A(H1N1)pdm09, State of São Paulo, Brazil, 2009. PLoS ONE, 2015. 10: e0118772.

13. Horby P, Nguyen NY, Dunstan SJ, Kenneth Baillie J. An updated systematic review of the role of host genetics in susceptibility to influenza. Influ Other Respir Viruses. 2013;7:37-41.

14. Antonopoulou A, Baziaka F, Tsaganos T, Raftogiannis M, Koutoukas P, Spyridaki A, Mouktaroudi M, Kotsaki A, Savva A, Georgitsi M, et al. Role of tumor necrosis factor gene single nucleotide polymorphisms in the natural course of 2009 influenza A H1N1 virus infection. Int J Inf Dis. 2012;16:e204-8.

15. Maestri, A., Sortica, V.A., Tovo-Rodrigues, L., Santos, M.C., Barbagelata, L., Moraes, M.R., Alencar de Mello, W., Gusmão, L., Sousa, R.C.M., Emanuel Batista dos Santos, S. Siaa2-3Galß1-receptor genetic variants are associated with influenza A(H1N1)pdm09 severity. PLoS ONE, 2015. 10: e0139681.

16. Zhou J, To KK, Dong H, Cheng ZS, Lau CC, Poon VK, Fan YH, Song YQ, Tse $\mathrm{H}$, Chan $\mathrm{KH}$, et al. A functional variation in CD55 increases the severity of 2009 pandemic H1N1 influenza A virus infection. J Inf Dis. 2012;206:495-503.

17. Zúñiga, J., Buendía-Roldán, I., Zhao, Y., Jiménez, L., Torres, D., Romo, J., Ramírez, G., Cruz, A., Vargas-Alarcon, G., Sheu, C.C., et al. Genetic variants associated with severe pneumonia in A/H1N1 influenza infection. Eur Respir J, 2012. 39: https://doi.org/10.1183/09031936.00020611.

18. Morales-García G, Falfán-Valencia R, García-Ramírez RA, Camarena Á, Ramirez-Venegas A, Castillejos-López M, Pérez-Rodríguez M, GonzálezBonilla C, Grajales-Muñíz C, Borja-Aburto V, et al. Pandemic influenza A/ H1N1 virus infection and TNF, LTA, IL1B, IL6, IL8, and CCL polymorphisms in Mexican population: a case-control study. BMC Infect Dis. 2012;12:1-9.

19. Bailey CC, Huang IC, Kam C, Farzan M. IFITM3 limits the severity of acute influenza in mice. PLoS Pathog. 2012;8:e1002909.

20. Brass AL, Huang IC, Benita Y, John SP, Krishnan MN, Feeley EM, Ryan B, Weyer JL, van der Weyden L, Fikrig E, et al. IFITM proteins mediate the innate immune response to influenza A H1N1 virus, West Nile Virus and Dengue Virus. Cell. 2009;139:1243-54.

21. Huang IC, Bailey CC, Weyer JL, Radoshitzky SR, Becker MM, Chiang JJ, Brass AL, Ahmed AA, Chi X, Dong L, et al. Distinct patterns of IFITM-mediated restriction of filoviruses, SARS coronavirus, and influenza A virus. PLoS Pathog. 2011;7:e1001258.

22. Lu J, Pan Q, Rong L, He W, Liu SL, Liang C. The IFITM proteins inhibit HIV-1 infection. J Virol. 2011;85:2126-37.

23. Zhang YH, Zhao Y, Li N, Peng YC, Giannoulatou E, Jin RH, Yan HP, Wu H, Liu $J \mathrm{H}$, Liu N, et al. Interferon-induced transmembrane protein-3 genetic variant rs 12252-C is associated with severe influenza in Chinese individuals. Nat Commun. 2013:4:1418.

24. Mehrbod P, Eybpoosh S, Fotouhi F, Shokouhi Targhi H, Mazaheri V, Farahmand B. Association of IFITM3 rs12252 polymorphisms, BMI, diabetes, and hypercholesterolemia with mild flu in an Iranian population. Virol J. 2017;14:1-8.

25. Turner DM, Williams DM, Sankaran D, Lazarus M, Sinnott PJ, Hutchinson IV An investigation of polymorphism in the interleukin-10 gene promoter. Eur J Immunogenet. 1997;24:1-8.

26. Garred P, Pressler T, Madsen HO, Frederiksen B, Svejgaard A, Høiby N, Schwartz M, Koch C. Association of mannose-binding lectin gene heterogeneity with severity of lung disease and survival in cystic fibrosis. J Clin Invest. 1999:104:431-7.

27. Ip WK, Chan KH, Law HK, Tso GH, Kong EK, Wong WH, To YF, Yung RW, Chow EY, Au KL, et al. Mannose-binding lectin in severe acute respiratory syndrome coronavirus infection. J Infect Dis. 2005;191:1697-704.

28. Tang YW, Cleavinger PJ, Li H, Mitchell PS, Smith TF, Persing DH. Analysis of candidate-host immunogenetic determinants in herpes simplex virusassociated Mollaret's meningitis. Clin Infect Dis. 2000:30:176-8.

29. McGuire W, Hill AV, Allsopp CE, Greenwood BM, Kwiatkowski D. Variation in the TNF-alpha promoter region associated with susceptibility to cerebral malaria. Nature. 1994;371:508-10.

30. Mira JP, Cariou A, Grall F, Delclaux C, Losser MR, Heshmati F, Cheval C, Monchi M, Teboul JL, Riché F, et al. Association of tnf2, a tnf-a promoter polymorphism, with septic shock susceptibility and mortality: A multicenter study. J Am Med Assoc. 1999;282:561-8.

31. Zhang Y, Zhang Z, Cao L, Lin J, Yang Z, Zhang X. A common CD55 rs 2564978 variant is associated with the susceptibility of non-small cell lung cancer. Oncotarget. 2017;8:6216-21.

32. Shang $Y$, Chai N, Gu Y, Ding L, Yang Y, Zhou J, Ren G, Hao X, Fan D, Wu $K$, et al. Systematic immunohistochemical analysis of the Eexpression of CD46, CD55, and CD59 in colon cancer. Arch Pathol Lab Med. 2014;138:910-9.

33. Bermejo-Martin JF, Martin-Loeches I, Rello J, Antón A, Almansa R, Xu L, Lopez-Campos G, Pumarola T, Ran L, Ramirez P, et al. Host adaptive immunity deficiency in severe pandemic influenza. Crit Care. 2010;14:R167-R167. 
34. Chen JZ, Huang SD, Ji CN, Pang RY, Xie Y, Xue JL. Identification, expression pattern, and subcellular location of human RIP isoforms. DNA Cell Biol. 2005:24:464-9.

35. Gabriel, S., Ziaugra, L., Tabbaa, D. SNP genotyping using the Sequenom MassARRAY IPLEX platform. Current Protocols in Human Genetics, 2009. 60 2.12.1-2.12.18.

36. Tang YW, Li H, Wu H, Shyr Y, Edwards KM. Host single-nucleotide polymorphisms and altered responses to inactivated influenza vaccine. J Infect Dis. 2007:196:1021-5.

37. Yang X, Tan B, Zhou X, Xue J, Zhang X, Wang P, Shao C, Li Y, Li C, Xia H, et al. Interferon-inducible transmembrane protein 3 genetic variant rs12252 and influenza susceptibility and severity: a meta-analysis. PLoS ONE. 2015;10:e0124985

38. Randolph AG, Yip WK, Allen EK, Rosenberger CM, Agan AA, Ash SA, Zhang Y, Bhangale TR, Finkelstein D, Cvijanovich NZ, et al. Evaluation of IFITM3 rs12252 association with severe pediatric influenza linfection. J Infect Dis. 2017;216:14-21.

39. Wellington $D$, Laurenson-Schafer $H$, Abdel-Haq A, Dong T. IFITM3: How genetics influence influenza infection demographically. Biomedical Journal. 2019:42:19-26.

40. Kalliolias GD, Ivashkiv LB. TNF biology, pathogenic mechanisms and emerging therapeutic strategies. Nat Rev Rheumatol. 2016;12:49-62.

41. McKinstry KK, Strutt TM, Buck A, Curtis JD, Dibble JP, Huston G, Tighe M, Hamada H, Sell S, Dutton RW, et al. IL-10 deficiency unleashes an influenza-specific Th17 response and enhances survival against highdose challenge. Journal of Immunology. 2009;182:7353-63.

42. Rojas JM, Avia M, Martín V, Sevilla N. IL-10: A multifunctional cytokine in viral infections. J Immunol Res. 2017;2017:6104054-6104054.

43. García-Ramírez RA, Ramírez-Venegas A, Quintana-Carrillo R, Camarena ÁE, Falfán-Valencia R, Mejía-Aranguré JM. TNF, IL6, and IL1B polymorphisms are associated with severe influenza $\mathrm{A}(\mathrm{H} 1 \mathrm{~N} 1)$ virus infection in the Mexican population. PLoS ONE. 2015;10:e0144832.

44. Rogo LD, Rezaei F, Marashi SM, Yekaninejad MS, Naseri M, Ghavami N, Mokhtari-Azad T. Seasonal influenza A/H3N2 virus infection and IL-1B IL-10, IL-17, and IL-28 polymorphisms in Iranian population. J Med Virol. 2016;88:2078-84.

45. Keshavarz M, Namdari H, Farahmand M, Mehrbod P, Mokhtari-Azad T, Rezaei F. Association of polymorphisms in inflammatory cytokines encoding genes with severe cases of influenza A/H1N1 and B in an Iranian population. Virology Journal. 2019;16:1-10.

46. Zhao N, Chen H-L, Chen Z-Z, Li J, Chen Z-B. IL-10-592 polymorphism is associated with IL-10 expression and severity of enterovirus 71 infection in chinese children. J Clin Virol. 2017;95:42-6.

47. Ferdinands JM, Denison AM, Dowling NF, Jost HA, Gwinn ML, Liu L, Zaki SR, Shay DK. A Pilot study of host genetic variants associated with influenza-associated deaths among children and young adults. Emerg Infect Dis. 2011;17:2294-302.

48. Choudhary ML, Alagarasu K, Chaudhary U, Kawale S, Malasane P, Gurav YK, Padbidri V, Kadam D, Sangle SA, Salvi S, et al. Association of single nucleotide polymorphisms in TNFA and IL10 genes with disease severity in influenza A/H1N1pdm09 virus infections: A study from Western India. Viral Immunol. 2018;31:683-8.

49. Super M, Gillies SD, Foley S, Sastry K, Schweinle JE, Silverman VJ, Ezekowitz RAB. Distinct and overlapping functions of allelic forms of human mannose binding protein. Nat Genet. 1992;2:50-5.
50. Gallagher PM, Lowe G, Fitzgerald T, Bella A, Greene CM, McElvaney NG, O'Neill SJ. Association of IL-10 polymorphism with severity of illness in community acquired pneumonia. Thorax. 2003;58:154-6.

51. Gomi K, Tokue Y, Kobayashi T, Takahashi H, Watanabe A, Fujita T, Nukiwa T. Mannose-binding lectin gene polymorphism is a modulating factor in repeated respiratory infections. Chest. 2004;26:95-9.

52. Dhand, N.K. and Khatkar, M.S. Statulator: An online statistical calculator. Sample Size Calculator for Estimating a Single Proportion. Accessed 14 August 2019 at http://statulator.com/SampleSize/ss1P.html; 2014.

53. Ornelas, A.M.d.M., Xavier-de-Carvalho, C., Alvarado-Arnez, L.E., RibeiroAlves, M., Rossi, Á.D., Tanuri, A., de Aguiar, R.S., Moraes, M.O., and Cardoso, C.C. Association between MBL2 haplotypes and dengue severity in children from Rio de Janeiro, Brazil. Memorias do Instituto Oswaldo Cruz, 2019. 114: e190004.

54. Ravetch JV, Bolland S. IgG Fc receptors. Annu Rev Immunol. 2001;19:275-90.

55. Boruchov AM, Heller G, Veri M-C, Bonvini E, Ravetch JV, Young JW. Activating and inhibitory lgG Fc receptors on human DCs mediate opposing functions. J Clin Investig. 2005;115:2914-23.

56. Duan J, Lou J, Zhang Q, Ke J, Qi Y, Shen N, Zhu B, Zhong R, Wang Z, Liu $L$, et al. A genetic variant rs1801274 in FCGR2A as a potential risk marker for Kawasaki disease: a case-control study and meta-analysis. PLoS ONE. 2014;9:e103329.

57. Bouglé A, Max A, Mongardon N, Grimaldi D, Pène F, Rousseau C, Chiche J-D, Bedos J-P, Vicaut E, Mira J-P. Protective effects of FCGR2A polymorphism in invasive pneumococcal diseases. Chest. 2012;142:1474-81.

58. Chatzopoulou F, Gioula G, Kioumis I, Chatzidimitriou D, Exindari M. Identification of complement-related host genetic risk factors associated with influenza $\mathrm{A}(\mathrm{H} 1 \mathrm{N1}$ )pdm09 outcome: challenges ahead. Med Microbiol Immunol. 2019;208:631-40.

59. Arcanjo AC, Mazzocco G, de Oliveira SF, Plewczynski D, Radomski JP. Role of the host genetic variability in the influenza A virus susceptibility. Acta Biochim Pol. 2014;61:403-19.

60. Zheng YH, Yu HF, Peterlin BM. Human p32 protein relieves a posttranscriptional block to HIV replication in murine cells. Nat Cell Biol. 2003:5:611-8.

61. Lee N, Cao B, Ke C, Lu H, Hu Y, Tam CHT, Ma RCW, Guan D, Zhu Z, Li H, et al. IFITM3, TLR3, and CD55 gene SNPs and cumulative genetic risks for severe outcomes in Chinese patients with H7N9/H1N1pdm09 influenza. J Infect Dis. 2017;216:97-104.

62. Park J, Seo T, Kim H, Choe J. Sumoylation of the novel protein hRIP\{beta\} is involved in replication protein A deposition in PML nuclear bodies. Mol Cell Biol. 2005;25:8202-14.

63. Ganna A. The Covid-Host Genetics Initiative; a global initiative to elucidate the role of host genetic factors in susceptibility and severity of the SARS-CoV-2 virus pandemic. Eur J Hum Genet. 2020;28:715-8.

64. Kachuri, L., Francis, S.S., Morrison, M., Boss, amp, amp, eacute, Y., Cavazos, T.B., Rashkin, S.R., Ziv, E., et al. The landscape of host genetic factors involved in infection to common viruses and SARS-CoV-2. MedRxiv, 2020. Preprint: 2020.05.01.20088054

\section{Publisher's Note}

Springer Nature remains neutral with regard to jurisdictional claims in published maps and institutional affiliations. 